\title{
Production of $O\left({ }^{1} D\right)$ from photolysis of $\mathrm{O}_{3}$
}

\author{
H. A. Michelsen ${ }^{a}$, R. J. Salawitch ${ }^{b}$, P. O. Wennberg ${ }^{a}$, and J. G. Anderson ${ }^{\text {a,b }}$
}

\begin{abstract}
We have used a model accounting for absorption by vibrationally and rotationally excited ozone $\left(\mathrm{O}_{3}\right)$ to examine published measurements of the quantum yield of $O\left({ }^{1} D\right)$ and $\mathrm{O}_{2}\left({ }^{1} \Delta_{\mathrm{g}}\right)$ from $\mathrm{O}_{3}$ photolysis in the Huggins band (305-325 $\mathrm{nm}$ ). We conclude that the quantum yield of $O\left({ }^{1} \mathrm{D}\right)$ is $0.2-0.3$ for wavelengths between 312 and $320 \mathrm{~nm}$ at $298 \mathrm{~K}$; in contrast, the JPL recommended quantum yield of $O\left({ }^{1} D\right)$ is negligible in this wavelength region. We present a compilation of our results at temperatures and wavelengths relevant to atmospheric calculations. Production of $O\left({ }^{1} D\right)$ from excited $\mathrm{O}_{3}$ increases calculated concentrations of $O\left({ }^{1} \mathrm{D}\right)$ by up to $40 \%$ and $\mathrm{OH}$ by $15 \%$ for the troposphere and lower stratosphere.
\end{abstract}

\section{Introduction}

Photolysis of ozone $\left(\mathrm{O}_{3}\right)$ produces $\mathrm{O}\left({ }^{1} \mathrm{D}\right)$ and $\mathrm{O}_{2}\left({ }^{1} \Delta_{\mathrm{g}}\right)$ with near unit efficiency at wavelengths shorter than $300 \mathrm{~nm}$. Near $310 \mathrm{~nm}$ the quantum yield of these species falls rapidly as the photolysis energy approaches the energetic limit for their production from ground-state $\mathrm{O}_{3}$. There is considerable controversy, however, concerning the value of the quantum yield of $O\left({ }^{1} \mathrm{D}\right), \Phi$, at wavelengths $(\lambda)$ longer than $310 \mathrm{~nm}$. For 298 K, JPL recommended values [DeMore et al., 1992] are $<0.1$ at $\lambda>315 \mathrm{~nm}$, where several measurements have yielded values exceeding 0.2 [Brock and Watson, 1980a; Martin et al., 1974; Trolier and Wiesenfeld, 1988]. The experimentally observed "tail" has been attributed to (1) spin-forbidden production of $\mathrm{O}\left({ }^{1} \mathrm{D}\right)+\mathrm{O}_{2}\left({ }^{3} \Sigma\right)$ [Brock and Watson, 1980a], (2) experimental artifact [DeMore et al., 1992], or (3) photolysis of vibrationally excited $\mathrm{O}_{3}$ [Adler-Golden et al., 1982; Trolier and Wiesenfeld, 1988].

Hypothesis (1) is inconsistent with the apparent correlation in the tail region between measurements of $\mathrm{O}_{2}\left({ }^{1} \Delta_{\mathrm{g}}\right)[\mathrm{B}$ all et al., 1993] and ${ }^{1}(\mathrm{D})$ [Brock and Watson, 1980a; Martin et al., 1974; Trolier and Wiesenfeld, 1988] (see Figure 1). Hypothesis (2) is based on measurements in which $\Phi$ was found to be negligible in the tail region [Arnold et al., 1977; Moortgat et al., 1977; Philen et al., 1977]. Measurements by Philen et al. appear to have been compromised by a wavelength-calibration error of $2 \mathrm{~nm}$ and are generally discounted [Brock and Watson, 1980a]. Moortgat et al. deconvolved their data to compensate for a photolysis source with low spectral resolution $(3.5-4.0 \mathrm{~nm})$, which may account for the absence of a tail in their published measurements. We have no explanation for the failure of Arnold et al. to observe the tail apparent in other experiments performed with similar techniques [Martin et al., 1974; Brock and Watson, 1980a].

\footnotetext{
Department of Chemistry and ${ }^{b}$ Department of Earth and Planetary Sciences, Harvard University
}

Copyright 1994 by the American Geophysical Union.

Paper number 94GL02052

0094-8534/94/94GL-02052\$03.00
The temperature dependence of $\Phi$ in the tail region provides a test of Hypothesis (3) since the population of $\mathrm{O}_{3}$ in vibrationally excited states falls with decreasing temperature. Data for $\Phi$ in the tail region for temperatures lower than $298 \mathrm{~K}$ are only available from the low resolution experiment by Moortgat et al. [1977], measurements made by Lin and Demore [1973] at $233 \mathrm{~K}$, and studies performed by Kuis et al. [1975] and Kajimoto and Cvetanovic [1976] only at $313 \mathrm{~nm}$. We have analyzed these data and those obtained at $298 \mathrm{~K}$ with a model that includes absorption by vibrationally and rotationally excited $\mathrm{O}_{3}$. The results confirm that $\Phi(298 \mathrm{~K})$ exceeds 0.2 in the tail region. This model can be used to predict $\Phi$ at temperatures outside of the range 233-298 K.

\section{A model for production of $O\left({ }^{1} D\right)$ from photolysis of $\mathbf{O}_{3}$}

As in previous studies [Adler-Golden et al., 1982; Hudson, 1980], we assumed that $\Phi$ at wavelength $\lambda$ and temperature $T$ is given by a sum over internal states, $v J K$, of the state-dependent quantum yield, $\Phi_{\mathrm{vJK}}(\lambda)$, weighted by the population in each state, $g\left(B_{v J K}(T)\right)$, and the vibrational-state-dependent absorption cross section, $\sigma_{v}(\lambda)$, i.e.,

$$
\Phi(\lambda, T)=\frac{1}{\sigma(\lambda, T)} \sum_{\mathrm{VJK}} \mathrm{g}\left(\mathrm{B}_{\mathrm{vJK}}(\mathrm{T})\right)\left(\sigma_{\mathrm{v}}(\lambda)\right)\left(\Phi_{\mathrm{vJK}}(\lambda)\right)
$$

where

$$
\sigma(\lambda, T)=\sum_{v J K} g\left(B_{v J K}(T)\right)\left(\sigma_{v}(\lambda)\right) .
$$

Here, $B_{v J k}(T)=\exp \left(-E_{\text {int }} / k T\right), k$ is the Boltzmann constant, $E_{\text {int }}$ is the internal energy determined from spectroscopic constants given in Herzberg [1966], $g$ is a rotational degeneracy factor assuming that $\mathrm{O}_{3}$ is nearly a symmetric top molecule, and $\sigma(\lambda, T)$ is the total absorption cross section.

Although calculated Franck-Condon factors or measured values of $\sigma_{v}(\lambda)$ have not been reported for excited states of $\mathrm{O}_{3}$ in the Huggins band, measurements of $\sigma(\lambda)$ have been performed as a function of temperature [A.M.Bass and R. J. Paur, unpublished data, 1984; Molina and Molina, 1986]. These measurements demonstrate weak vibrational structure corresponding to transitions into locally bound regions of the excited potential [Simons et al., 1973; Sinha et al., 1986]. For wavelengths between 300 and $325 \mathrm{~nm}$, the absorption cross section increases with temperature between 203 and $298 \mathrm{~K}$.

We derived an estimate of $\sigma_{\mathrm{v}}(\lambda)$ for the first vibrationally excited state of each of the three vibrational modes by performing a nonlinear least-squares (NLS) fit of Eq. (2) to the data of Bass and Paur (which cover a broader range of temperatures than other measurements). Values of $\sigma_{v}(\lambda)$ are given in Table 1, along with the assignment of features where transitions have been identified. We assumed that $\sigma_{\mathrm{v}}$ does not vary with rotational state. Following Adler-Golden et al. [1982], we assumed that molecules with one quantum of vibration $(v=1)$ in the asymmetric stretch have the same absorption 


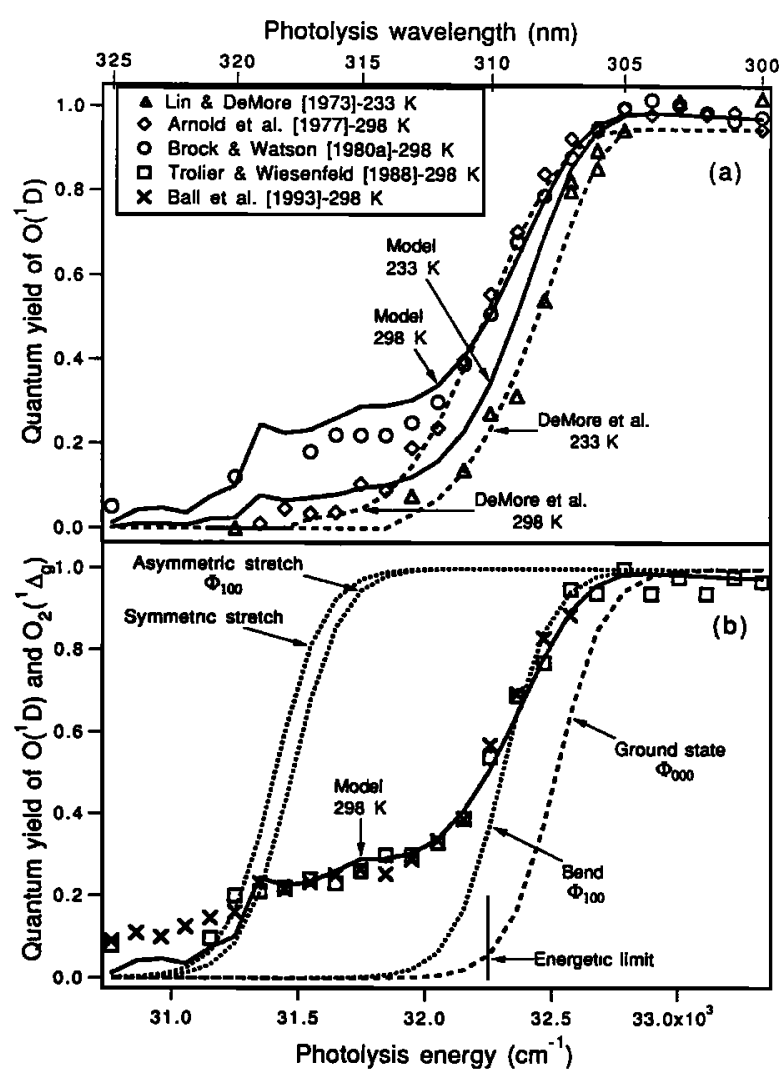

Figure 1. Model results compared with measured $\Phi$. The solid lines are the fit to the circles and triangles for $\lambda \leq 311 \mathrm{~nm}$. Each data set (symbols) was normalized to give $\Phi(305 \mathrm{~nm})=1$, except for that of Ball et al. [1993], which was normalized to 0.945 at $306 \mathrm{~nm}$. For clarity error bars are not included. (a) The dashed lines are the recommendations of DeMore et al. [1992]. (b) The dashed line is predicted for molecules with no initial internal energy. The dotted lines are predicted for the ground rotational state and the first vibrationally excited state of the asymmetric and symmetric stretches and the bend.

cross section as those with $(v=1)$ in the symmetric stretch but allowed those with $(v=1)$ in the bend and those in the ground state to have different cross sections.

Derived values of $\sigma_{\mathrm{v}}(\lambda)$ were used in a fit to quantum yield data to determine $\Phi_{\mathrm{vJK}}(\lambda)$. The simplest analysis would model $\Phi_{\mathrm{vJK}}(\lambda)$ as a unit step function shifted to lower energy (longer wavelength) from the energetic threshold by an amount equivalent to the internal energy of the molecule. A molecule with sufficient internal energy, however, may not photodissociate via the $O\left({ }^{1} \mathrm{D}\right)+\mathrm{O}_{2}\left({ }^{1} \Delta_{\mathrm{g}}\right)$ channel, despite its accessibility. We thus let $\Phi_{\mathrm{vJK}}(\lambda)$ have the form of a switching function with a finite, adjustable width $W_{v}$, i.e.,

$$
\Phi_{\mathrm{vJK}}(\lambda)=\frac{1}{2}\left[1+\operatorname{Tanh}\left(\frac{v-v_{\mathrm{vJK}}}{\mathrm{W}_{\mathrm{v}}}\right)\right],
$$

where $v$ is the photolysis energy in wavenumbers, and $v_{\mathrm{vJK}}$ is a state-dependent threshold (marking the inflection point of the switching function) shifted from the threshold for molecules possessing no internal energy $\left(v_{000}\right)$ by an amount related to the rotational $\left(E_{r o t}\right)$ and vibrational $\left(E_{v i b}\right)$ energy associated with state vJK (see Figure 1b). Thus,

$$
v_{v K K}=v_{000}-\varepsilon_{v i b} E_{v i b}-\varepsilon_{\text {rot }} E_{\text {rot }} \text {, }
$$

where $\varepsilon_{\mathrm{v}, \mathrm{b}}$ and $\varepsilon_{\text {rot }}$ account for the efficiency of coupling between the molecule's internal energy and the $O\left({ }^{1} D\right)+\mathrm{O}_{2}\left({ }^{1} \Delta_{g}\right)$ photolysis channel. These parameters are less than unity if initial internal energy of the molecule is partitioned into internal or translational energy of the photolytic products. We allowed $\varepsilon_{\text {vib }}, \varepsilon_{\text {rot }}, W_{v}$, and $v_{000}$ to be adjustable parameters in our model.

The sensitivity of $\Phi$ to temperature is governed by these state-dependent parameters. We performed a weighted NLS fit to quantum yield data for $233 \mathrm{~K}$ [Lin and Demore, 1973] and for $298 \mathrm{~K}$ [Brock and Watson, 1980a] (normalized to unity at 305 $\mathrm{nm}$ to bring the $308 \mathrm{~nm}$ value into agreement with the absolute measurement of Greenblatt and Wiesenfeld [1983]). Since there is disagreement among published measurements concerning the existence of the tail, data for wavelengths longer than $311 \mathrm{~nm}$ were excluded from our fits; the model was used to predict values of $\Phi$ in this region.

In our fits the data for $298 \mathrm{~K}$ were given five times the weight of the data for $233 \mathrm{~K}$ to reflect our greater confidence in these measurements. The data for $298 \mathrm{~K}$ to which we fit our model are consistent with numerous other measurements [Arnold et al., 1977; Trolier and Wiesenfeld, 1988; Ball et al. 1993], and the results are insensitive to the specific data set chosen for analysis. The data used for $233 \mathrm{~K}$ may have larger uncertainties (not estimated by $L$ in and Demore [1973]) than the $298 \mathrm{~K}$ data since the detection method used at $233 \mathrm{~K}$ was less direct. We did not use the data of Moortgat et al. [1977] because their spectral resolution $(3.5-4.0 \mathrm{~nm})$ was insufficient to sample the sharp feature in the fall-off region.

The NLS fit of Eq. (1) to the data gives $v_{000}=32518 \mathrm{~cm}^{-1}$, $\varepsilon_{\text {vib }}\left(v_{1}, v_{3}\right)=\varepsilon_{\text {rot }}=1, \varepsilon_{\text {vib }}\left(v_{2}\right)=0.300$, and $W_{v}=190 \mathrm{~cm}^{-1}$. Figure $1 b$ shows the prediction of $\Phi_{\mathrm{vJK}}(\lambda)$ for molecules possessing no internal energy and for molecules with one quantum of energy in each of the three vibrational modes, symmetric stretch $\left(v_{1}\right)$,

Table 1. Cross sections and parameters for Eq. (5)

\begin{tabular}{ccccccc}
\hline $\begin{array}{c}\lambda \\
(\mathrm{nm})\end{array}$ & $\sigma_{000}$ & $\begin{array}{c}\sigma_{\mathrm{y} 1, v 3} \\
\left(10^{-20} \mathrm{~cm}^{2}\right)\end{array}$ & $\sigma_{v 2}$ & Transition & $\mathbf{A}$ & $\begin{array}{c}\mathrm{B} \\
\left(\mathrm{cm}^{-1}\right)\end{array}$ \\
\hline 305 & 16.1 & 261 & 68.7 & & 1.01 & 3.933 \\
306 & 14.7 & 263 & 39.9 & & 1.01 & 11.51 \\
307 & 12.6 & 283 & 27.1 & & 1.05 & 33.09 \\
308 & 11.3 & 280 & 6.75 & & 1.15 & 79.39 \\
309 & 9.93 & 228 & 26.8 & & 1.39 & 159.9 \\
310 & 8.04 & 193 & 20.9 & & 1.90 & 272.5 \\
311 & 7.24 & 180 & 18.8 & & 2.93 & 407.9 \\
312 & 6.13 & 159 & 15.0 & & 4.87 & 551.4 \\
313 & 5.19 & 146 & 14.4 & & 8.21 & 682.3 \\
314 & 4.89 & 149 & 6.46 & & 13.3 & 791.6 \\
315 & 3.89 & 130 & 4.68 & & 17.6 & 851.3 \\
316 & 3.65 & 111 & 0.609 & & 20.4 & 903.8 \\
317 & 3.06 & 98.6 & 10.8 & & 18.0 & 900.3 \\
318 & 2.90 & 98.3 & 0 & & 21.8 & 948.4 \\
319 & 1.69 & 101 & 3.97 & $530 \leftarrow 100$ & 18.1 & 891.1 \\
320 & 2.69 & 65.6 & 0.978 & & 17.2 & 1066 \\
321 & 1.05 & 43.6 & 18.3 & $430 \leftarrow 010$ & 7.99 & 969.4 \\
322 & 2.04 & 38.1 & 5.04 & & 11.5 & 1201 \\
323 & 1.32 & 65.7 & 1.45 & & 14.3 & 1182 \\
324 & 0.663 & 59.0 & 2.10 & & 10.7 & 1152 \\
325 & 1.40 & 33.6 & 1.40 & & 11.8 & 1435 \\
\hline
\end{tabular}


bend $\left(v_{2}\right)$, and asymmetric stretch $\left(v_{3}\right)$. Only molecules with internal energy contribute to $\Phi$ beyond the energetic limit. This conclusion is supported by measurements that show that $\Phi$ increases dramatically at $314.5 \mathrm{~nm}$ when the asymmetric stretch is excited with an infrared laser [Zittel and Little, 1980].

A comparison of calculated and measured $\Phi$ is shown in Figure 1. The predicted value of $\Phi$ for $\lambda>311 \mathrm{~nm}$ at $298 \mathrm{~K}$ reproduces the tail in the data of Trolier and Wiesenfeld [1988] and Ball et al. [1993] within experimental uncertainty. The model also agrees very well with the results of Kuis et al. [1975] at $313 \mathrm{~nm}$ over temperatures from 221 to $293 \mathrm{~K}$ but is systematically lower than results from a similar study by Kajimoto and Cvetanovic' [1976]. The temperature dependence of $\Phi$ between 305 and $311 \mathrm{~nm}$ results from the photolysis of molecules populating excited rovibrational states. The model, however, systematically overestimates $\Phi$ at $233 \mathrm{~K}$. The discrepancy may result from: (1) uncertainties in $\sigma_{\mathrm{v}}(\lambda)$, the determination of which is limited by our understanding of the spectroscopy associated with structure in the absorption spectra (e.g., shifts in the rotational distribution near vibrational resonances cause the cross section to be nonmonotonic with temperature) or (2) large uncertainties for the $233 \mathrm{~K}$ data.

Significant production of $O\left({ }^{1} \mathrm{D}\right)$ at $312-320 \mathrm{~nm}$ is in sharp contrast to the recommendations of DeMore et al. [1992] and those from J. Phys. Chem. Ref. Data [Atkinson et al., 1992], which give $\Phi=0$ for wavelengths longer than $317 \mathrm{~nm}$ at $298 \mathrm{~K}$ and $313 \mathrm{~nm}$ at $233 \mathrm{~K}$. These recommendations are based on the data of Arnold et al. [1977], Brock and Watson [1980a], and Trolier and Wiesenfeld [1988] (without the tail) at $298 \mathrm{~K}$ and Moortgat et al. [1977] at lower temperatures. Results for the model of Adler-Golden et al. [1982] fall within the experimental uncertainty of the data of Brock and Watson [1980a] in the tail region. This model may have been discounted previously since it relies on analysis of data in the tail region, which had been suspected of resulting from an experimental artifact [DeMore et al., 1992].

To facilitate use of our results in atmospheric calculations, we parameterized output from the full model in the range 305 $325 \mathrm{~nm}$ according to the form

$$
\Phi(\lambda, T)=A(\lambda) \exp \left[\frac{-B(\lambda)}{k T}\right]
$$

Results, given in Table 1, reproduce full model predictions to within $10 \%$ for temperatures in the range $185-320 \mathrm{~K}$.

Figure 2 shows $\Phi$ for the spectral range 222-325 nm. All data are for $298 \mathrm{~K}$, except the data of Lin and Demore [1973], which do not deviate significantly from other values, supporting evidence [Steinfeld et al., 1987] that $\Phi$ is independent of temperature in this wavelength region. For $\lambda<305 \mathrm{~nm}, \Phi$ falls steadily with decreasing wavelength. A linear fit to data of Trolier and Wiesenfeld [1988] yields

$$
\Phi(\lambda)=1.98-\frac{301 \mathrm{~nm}}{\lambda} \text { for } 271<\lambda<305 \mathrm{~nm}
$$

For $222 \leq \lambda \leq 271 \mathrm{~nm}, \Phi=0.87$ within experimental uncertainty. These results are in better agreement with experiment than those of DeMore et al. [1992] (see Figure 2).

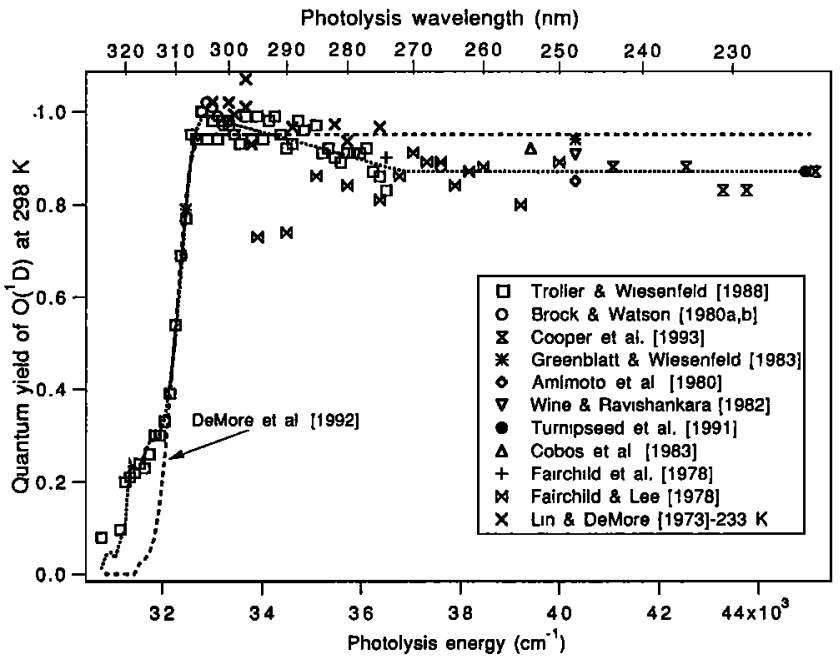

Figure 2. $\Phi$ at wavelengths $222-325 \mathrm{~nm}$. The model is given by Table 1 and Eq. (5) (T=298 K) for $\lambda \geq 305 \mathrm{~nm}$, Eq. (6) for $271<\lambda<305 \mathrm{~nm}$, and a constant $(0.87)$ for $222 \leq \lambda \leq 271 \mathrm{~nm}$. Error bars have been removed for clarity.

\section{Atmospheric implications}

Production of nitrogen oxides from the decomposition of $\mathrm{N}_{2} \mathrm{O}$ is regulated by the concentration of $\mathrm{O}\left({ }^{1} \mathrm{D}\right)$ in the stratosphere. Global amounts of $\mathrm{OH}$, the primary oxidant of numerous carbon, hydrogen, nitrogen, and sulfur compounds, are controlled by reaction of $\left.\mathrm{O}^{3} \mathrm{D}\right)$ with $\mathrm{H}_{2} \mathrm{O}$. Reactions involving $\mathrm{OH}$ and $\mathrm{HO}_{2}$ are a major sink for $\mathrm{O}_{3}$ in the upper and lower stratosphere [P. O. Wennberg, submitted, 1994].

Calculated concentrations of $O\left({ }^{1} D\right)$ and $O H$ for the lower stratosphere are larger by as much as 40 and $15 \%$, respectively, compared to results from models that neglect photolysis of excited $\mathrm{O}_{3}$, as shown in Figure 3. Effects are larger in the lower than in the upper stratosphere because at lower altitudes production of $\left.O{ }^{1} D\right)$ from photolysis of $\mathrm{O}_{3}$ occurs at longer wavelengths. Concentrations of $O\left({ }^{1} D\right)$ in the tropical

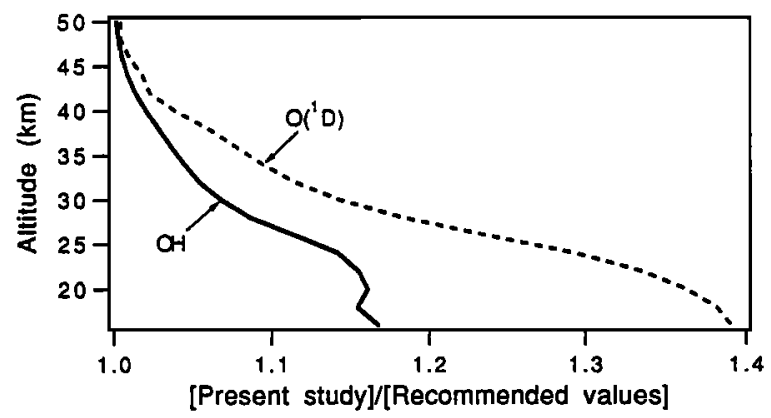

Figure 3. Comparison of calculated stratospheric concentrations. Shown for $O H$ (solid line) and $O\left({ }^{1} \mathrm{D}\right)$ (dotted line) is the ratio of the 24 hour concentration or $30 \mathrm{~N}$ at equinox, calculated using $\Phi$ given by Table 1 and Eqs. (5) and (6), relative to concentrations calculated using recommended values [DeMore et al., 1992]. Results were obtained using a photochemical model constrained by data for $\mathrm{O}_{3}, \mathrm{H}_{2} \mathrm{O}$, and $\mathrm{CH}_{4}$ from the Atmospheric Trace Molecule Spectroscopy Experiment, for aerosol loading typical of non-volcanic conditions [Minschwaner et al., 1993]. 
troposphere increase by $20-40 \%$; those of $\mathrm{OH}$ increase by 3 $14 \%$ [D. J. Jacob, private communication, 1994].

\section{Conclusions}

Our study suggests that photolysis of vibrationally excited $\mathrm{O}_{3}$ is responsible for production of $O\left({ }^{1} \mathrm{D}\right)$ for wavelengths between 311 and $320 \mathrm{~nm}$. We have developed a model that predicts the quantum yield of $O\left({ }^{1} D\right)$ in the wavelength range 222-325 nm at temperatures relevant for atmospheric calculations, including temperatures outside the range of measurements (233-298 K). Lower stratospheric concentrations of $O\left({ }^{1} \mathrm{D}\right)$ and $\mathrm{OH}$ calculated using our model are increased by as much as $40 \%$ and $15 \%$, respectively, compared to results from models that use recommended values for the quantum yield. The importance of $O\left({ }^{1} D\right)$ and $O H$ for regulating the composition of the global atmosphere underscores the need for additional laboratory measurements of the production of $O\left({ }^{1} D\right)$ at high spectral resolution and temperatures characteristic of the lower stratosphere $(\sim 220 \mathrm{~K})$.

Acknowledgments. We thank the National Science Foundation for support of H. A. Michelsen through an NSF Postdoctoral Fellowship.

\section{References}

Adler-Golden, S. M., E. L. Schweitzer, and J. I. Steinfeld, Ultraviolet continuum spectroscopy of vibrationally excited ozone, $J$. Chem. Phys., 76, 2201, 1982.

Amimoto, S. T. et al., Direct observation of $O\left({ }^{3} \mathrm{P}_{\mathrm{J}}\right)$ in the photolysis of $\mathrm{O}_{3}$ at $248 \mathrm{~nm}, J$. Chem. Phys., 73, 1244, 1980.

Amold, I., F. J. Comes, and G. K. Moortgat, Laser flash photolysis: quantum yield of $O\left({ }^{1} D\right)$ formation from ozone, Chem. Phys., 24, 211, 1977.

Atkinson, R. et al., Evaluated Kinetic and Photochemical Data for Atmospheric Chemistry, J. Phys. Chem. Ref. Data, 21, 1156, 1992.

Ball, S. M. et al., The relative quantum yields of $O\left(a^{1} \Delta_{g}\right)$ from the photolysis of ozone in the wavelength range $270 \mathrm{~nm} \leq \lambda \leq 329 \mathrm{~nm}$, Geophys. Res. Lett., 20, 2063, 1993.

Brock, J. C., and R. T. Watson, Laser flash photolysis of ozone: $O\left({ }^{1} D\right)$ quantum yields in the fall-off region 297-325 nm, Chem. Phys., 46, 477, 1980a.

Cobos, C., E. Castellano, and H. J. Schumacher, The kinetics and the mechanism of ozone photolysis at $253.7 \mathrm{~nm}$, J. Photochem., 21, 291, 1983.

Cooper, 1. A., P. J. Neill, and J. R. Wiesenfeld, Relative quantum yield of $O\left({ }^{1} D_{2}\right)$ following ozone photolysis between 221 and $243.5 \mathrm{~nm}, J$. Geophys. Res., 98, 12,795, 1993.

DeMore, W. B. et al., Chemical kinetics and photochemical data for use in stratospheric modeling, Evaluation number 10, JPL Publication $92-$ 20, 1992.

Fairchild, C. E., E. J. Stone, and G. M. Lawrence, Photofragment spectroscopy of ozone in the uv region $270-310 \mathrm{~nm}$ and at $600 \mathrm{~nm}, J$. Chem. Phys., 69, 3632, 1978.

Fairchild, P. W., and E. K. C. Lee, Relative quantum yields of $O\left({ }^{1} D\right)$ in ozone photolysis in the region between 250 and $300 \mathrm{~nm}$, Chem. Phys. Lett., 60, 36, 1978.
Greenblatt, G. D., and J. R. Wiesenfeld, Time-resolved resonance fluorescence studies of $\left.\mathrm{O}^{1} \mathrm{D}_{2}\right)$ yields in the photodissociation of $\mathrm{O}_{3}$ at 248 and $308 \mathrm{~nm}, J$. Chem. Phys., 78, 4924, 1983.

Herzberg, G., Molecular spectra and molecular structure III. Electronic spectra and electronic structure of polyatomic molecules, Van Nostrand Reinhold Co., New York, 1966.

Hudson, R. D., Temperature dependence of ozone absorption cross section, 280 to $330 \mathrm{~nm}$, Quadrennial International Ozone Symposium, ed. J. London, Boulder, CO, 146, 1980.

Kajimoto, O., and R. J. Cvetanovic, Temperature dependence of $O\left({ }^{1} D_{2}\right)$ production in the photolysis of ozone at $313 \mathrm{~nm}$, Chem. Phys. Lett., $37,533,1976$.

Kuis, S., R. Simonaitis, and J. Heicklen, Temperature dependence of the photolysis of ozone at $3130 \AA$, J. Geophys. Res., 80, 1328, 1975.

Lin, C.-L., and W. B. DeMore, $O\left(^{1} D\right)$ production in ozone photolysis near $3100 \AA$, J. Photochem., 2, 161, 1973.

Martin, D., J. Girman, and H. S. Johnston, 167th ACS National Meeting, Los Angeles, 1974.

Minschwaner, K., R. J. Salawitch, and M. B. McElroy, Absorption of solar radiation by $\mathrm{O}_{2}$ : implications for $\mathrm{O}_{3}$ and lifetimes for $\mathrm{N}_{2} \mathrm{O}$, $\mathrm{CFCl}_{3}$, and $\mathrm{CF}_{2} \mathrm{Cl}_{2}$, J. Geophys. Res., 98, 10543, 1993.

Molina, L. T., and M. J. Molina, Absolute absorption cross sections of ozone in the 185- to 350-nm wavelength range, J. Geophys. Res., 91, $14,501,1986$.

Moortgat, G. K., E. Kudszus, and P. Warneck, Temperature dependence of $O\left({ }^{1} D\right)$ formation in the near U.V. photolysis of ozone, J. Chem. Soc. Faraday Trans., 73, 1216, 1977.

Philen, D. L., R. T. Watson, and D. D. Davis, A quantum yield determination of $O\left({ }^{1} D\right)$ production from ozone via laser flash photolysis, J. Chem. Phys., 67, 3316, 1977.

Simons, J. W. et al., Ozone ultraviolet photolysis. VI. The ultraviolet spectrum, J. Chem. Phys., 59, 1203, 1973.

Sinha, A. et al., Excitation spectroscopy of jet-cooled ozone: The Huggins system, J. Chem. Phys., 84, 6108, 1986.

Steinfeld, J. I., S. M. Adler-Golden, and J. W. Gallagher, Critical survey data on the spectroscopy and kinetics of ozone in the mesosphere and thermosphere, J.Phys. Chem. Ref. Data, 16, 911, 1987.

Trolier, M., and J. R. Wiesenfeld, Relative quantum yield of $O\left({ }^{1} D_{2}\right)$ following ozone photolysis between 275 and $325 \mathrm{~nm}, J$. Geophys. Res., 93, 7119, 1988.

Turnipseed, A. A. et al., The photochemistry of ozone at 193 and 222 nm, J. Chem. Phys., 95, 3244, 1991.

Wine, P. H., and A. R. Ravishankara, $\mathrm{O}_{3}$ photolysis at $248 \mathrm{~nm}$ and $\mathrm{O}\left({ }^{1} \mathrm{D}_{2}\right)$ quenching by $\mathrm{H}_{2} \mathrm{O}, \mathrm{CH}_{4}, \mathrm{H}_{2}$, and $\left.\mathrm{N}_{2} \mathrm{O}: \mathrm{O}^{3} \mathrm{P}_{\mathrm{J}}\right)$ yields, Chem. Phys., 69, 365, 1982.

Zittel, P. F., and D. D. Little, Photodissociation of vibrationally excited ozone, J. Chem. Phys., 72, 5900, 1980.

J. G. Anderson, H. A. Michelsen, P. O. Wennberg, Harvard Univ., Dept. of Chemistry, 12 Oxford St., Cambridge, MA 02138

R. J. Salawitch, Harvard Univ., Dept. of Earth and Planetary Sciences, 29 Oxford St., Cambridge, MA 02138

(Received March 30, 1994; last revised July 8, 1994; accepted July 27,1994 .) 